\title{
De Domingos Jorge Velho a Zumbi dos Palmares: uma análise semântico-enunciativa da nomeação e da renomeação de uma rua
}

\author{
From Domingos Jorge Velho to Zumbi dos Palmares: a semantic-enunciative analysis \\ of the process of naming and renaming a street
}

Anderson Braga do Carmo ${ }^{1}$

Doutorando do Programa de Pós-graduação em Linguistica da Universidade Estadual de das Ideias Linguísticas.

E-mail: andersonbdocarmo@hotmail.com
RESUMO: Neste estudo, buscamos refletir sobre o funcionamento semântico-enunciativo da nomeação e posterior renomeação de uma rua da cidade de São José do Rio Preto-SP, sendo esta rua nomeada primeiramente de Rua Domingos Jorge Velho e posteriormente de Rua Zumbi dos Palmares. Verificamos os processos de designação da devida via tentando apreender uma questão fundamental da configuração evenemencial: o que o acontecimento da nomeação e o da renomeação recortaram como memoráveis para significar e ressignificar uma rua da cidade? 0 pressuposto que embasa este estudo é o de que o sentido da linguagem localiza-se no estudo da enunciação, do acontecimento do dizer, o que nos coloca na perspectiva teórico-metodológica da Semântica do Acontecimento (GUIMARÃES, 2002). Depreendemos, então, que os diferentes recortes de textos mobilizados em nossa análise significam por rememorações diferentes, nomeando ora Domingos Jorge Velho, ora Zumbi dos Palmares como sujeitos merecedores de homenagem, e aptos, ou não, para significar uma rua da cidade. Assim, a partir da nossa análise, verificamos que o nome de uma rua e sua substituição aparecem como modos incontornáveis de erigir algo em acontecimento, o que nos leva a compreender que, ao receber um nome, uma rua passa a ter também concretude histórica.

Palavras-chave: Rua; Significação; Memorável.

ABSTRACT: In this study, we seek to reflect on the semantic-enunciative functioning of the naming process and subsequent renaming of a street in the city of São José do Rio Preto-SP, which was first named Domingos Jorge Velho Street and later Zumbi dos Palmares Street. We verified the name designation processes of the above-mentioned street in order to try to understand the key point of the evenemencial setting: what do the events of naming and renaming choose as memorable to mean a city street? This study is based on the assumption that the meaning of language is located in the study of enunciation, which puts us in the theoretical and methodological perspective of the Semantics of the Event (GUIMARÃES, 2002). We inferred, then, that the different texts mobilized in our analysis mean because of different rememorizing, naming the street sometimes Domingos Jorge Velho sometimes Zumbi dos Palmares as honorable subjects, and able, or not, to mean a city street. Therefore, from our analysis, we verified that the name of the street and its replacement appear as ways to transform something in event, what leads us to understand that, when receiving a name, a street also receives historical concreteness.

KEYWoRDS: Street; Meaning; Memorable. 


\section{Introdução}

Dara Guimarães (1991, p. 53), “a Cidade é um espaço cada vez mais habitado por palavras". Nessa linha de pensamento, verificar como a linguagem se espacializa, e ainda mais especificamente, funciona neste lugar de dizer é uma das pretensões deste artigo, que intenta compreender o sentido e o funcionamento designativo de nomes de rua.

Neste estudo, vamos trazer para a reflexão, a partir de um conjunto heteróclito de textos (mapas, placas de denominação de logradouros públicos, decretos, projetos e leis), como se deu o funcionamento semânticoenunciativo de um caso específico da cidade de São José do Rio Preto (SP), o da nomeação e posterior renomeação de uma rua. Sendo esta rua nomeada primeiramente de Rua Domingos Jorge Velho e posteriormente de Rua Zumbi dos Palmares. Considerando o presente fato, verificamos como se deram os processos de designação da devida via, tentando apreender um aspecto fundamental da configuração evenemencial: o que o acontecimento da nomeação e o da renomeação recortam como memoráveis para significar e ressignificar uma rua da cidade, dando-lhe assim existência histórica?

Desse modo, a premissa que embasa este estudo é a de que o sentido da linguagem se localiza no estudo da enunciação, do acontecimento do dizer, o que nos coloca na perspectiva teórico-metodológica da Semântica do Acontecimento, domínio que leva em conta que "o que se diz é incontornavelmente construído na linguagem" (GUIMARÃES, 2002, p. 7).

Sobre o funcionamento semântico da nomeação, temos que o que um nome designa é construído simbolicamente, ou seja, "esta construção se dá porque a linguagem funciona por estar exposta ao real enquanto constituído materialmente pela história" (GUIMARÃES, 2002, p. 91).

Então, já que nos prestamos a falar de designação, vale destacar a diferença que Guimarães (2002, p. 9) faz entre referência, nomeação e designação. Para o semanticista, a "nomeação é o funcionamento semântico pelo qual algo recebe um nome" (GUIMARÃES, 2002, p. 9), "a designação é o que se poderia chamar de significação de um nome", "seria a significação enquanto algo próprio das relações de linguagem, mas enquanto uma relação linguística (simbólica) remetida ao real, exposta ao real, ou seja, enquanto uma relação tomada na história" (GUIMARÃES, 2002, p. 9). E a referência é "vista como a particularização de algo na e pela enunciação" (GUIMARÃES, 2002, p. 9).

Nessa perspectiva, e no que diz respeito à relação da linguagem com as coisas, o que nos interessa saber é como, ao dizer algo, fala-se das coisas. Para Guimarães (1991, p. 54), "os nomes de espaço na cidade, e o que os acompanha, não só ocupam lugar neste espaço de vida, como lhe dão sentidos e constroem de algum modo esta geografia. Identificam-na”. Dessa maneira, para o autor, "um nome, ao designar, funciona como elemento das relações sociais que ajuda a construir e das quais passa a fazer parte" (GUIMARÃES, 1991, p. 54).

Nesta pesquisa, veremos que o nome de uma rua e sua substituição aparecem como modos incontornáveis de erigir algo em acontecimento da história, o que nos leva a compreender que ao receber um nome, uma rua passa a ter existência histórica (GUIMARÃES, 1991, p. 54). Visto isso, especificaremos as conjunturas desse processo.

\section{Sobre o acontecimento da nomeação e da renomeação de uma rua}

Dentro do quadro teórico-metodológico da Semântica do Acontecimento, tem recebido uma atenção especial a temática da cidade. Assim, nos trabalhos desenvolvidos por Guimarães em 1991, 2001 e 2002, notamos que o semanticista toma os nomes de ruas como objeto de análise, considerando o processo de nomeação de vias como mais um "modo de questionar as 
posições informacionais no modo como tratam a relação da linguagem com as coisas, com o mundo".

Filiando-nos a esta linha de pensamento, buscaremos colocar em evidência esta relação entre a linguagem e as coisas - Linguagem/Cidade - sendo que, no caso específico deste artigo, a relação que se coloca é entre nomes, os sujeitos a quem referem, e o fato da nomeação e da renomeação de uma rua da cidade de São José do Rio Preto.

De acordo com Guimarães (2002, p. 45), quanto à estrutura morfossintática, os nomes de ruas podem ser nomes próprios de pessoas, nomes próprios topográficos, sintagmas preposicionados, números etc. Em nosso artigo, daremos espaço para refletir sobre os processos de nomeação de uma rua determinados por nomes próprios de pessoas.

Com isso, para iniciarmos um percurso de análise, objetivamos compreender primeiramente como se dá o processo de nomear uma rua: Quem se responsabiliza por esta nomeação? Quais critérios são utilizados para que uma rua seja nomeada com um nome próprio de pessoa?

Descobrimos desse ensejo que os processos de nomeação de ruas, em São José do Rio Preto, ficam a cargo do poder legislativo da cidade. É na Câmara Municipal onde se promulgam ou não as nomeações em forma de Lei, que são feitas mediante projeto formulado por algum de seus representantes. Desta forma, notamos que a performatividade da nomeação, em forma de Lei, se formula na Câmara, e é sancionada ou pelo prefeito, ou pelo presidente da mesma. Assim, todas as vezes que nesse artigo fizermos referência aos processos de nomeação de uma via, tomaremos este lugar do dizer como o responsável pela nomeação, e que será sempre representado em nossa análise por um locutor-administrador, que agencia do lugar da legislação.

No entanto, vale destacar que, geralmente, nestas leis, como aponta Guimarães (2011, p. 140), "a denominação é significada como centro do que se enuncia", ou seja, "não interessa quem atribui a denominação, mas quem a recebe e como". Veremos que o nosso corpus permitirá que ora concordemos e ora discordemos deste pressuposto.

Enfim, consideremos agora outro ponto: os critérios utilizados para se nomear uma rua com um nome próprio de pessoa.

Segundo a Lei no 885 , sancionada e promulgada pelo prefeito Dr. Philadelpho Gouveia Neto, em 23 de novembro de 1962, todo projeto que viesse a dar nome de pessoas às ruas da cidade de São José do Rio Preto deveria ser fundamentado e apresentar três requisitos:

a) biografia resumida da pessoa homenageada com a denominação;

b) referência especial e trabalhos realizados - em qualquer campo de atividade, com influência notória na vida coletiva; ou

c) gestos de filantropia, de abnegação ou de heroísmo, com repercussão geral.

De acordo com essa lei, alguns aspectos do funcionamento semânticoenunciativo da nomeação precisam ser destacados e outros melhor explicitados. Primeiro, a denominação que impõe o item $a$, diz respeito não apenas ao nome da rua, mas incluso uma designação que fosse representativa do sujeito referido, que justificasse a homenagem, e que estaria presente na placa de denominação da rua como um aposto.

Segundo, vemos que os nomes de ruas cuja estrutura morfossintática seja um nome próprio de pessoa não funcionam apenas pelo seu aspecto cotidiano, do endereço, mas é também o lugar da homenagem.

E, por fim, podemos considerar que, para tornar-se denominação de logradouro, ou seja, para que um nome passe a denominar uma rua, é preciso que o sujeito homenageado tenha realizado trabalhos, ou tenha exercido profissão com influência "notória" na vida coletiva, ou que tenha realizado gestos de filantropia, de abnegação ou de heroísmo com repercussão geral. Desta forma, nota-se que o sujeito se significa pelos atos prestados a uma 
história. Ou seja, a enunciação que nomeia uma rua toma como justificativa e autorização algum aspecto específico de uma enunciação anterior na qual funciona este nome.

Desse modo, a presente lei busca atribuir ao ato de nomear uma legitimação pela história. Afinal, o que sustenta e designa o ordenamento jurídico da nomeação é o fato, o acontecimento o qual está inscrito e significa este nome. Assim, se este nome puder ser enquadrado dentro das condições impostas pela lei, tem-se autorizada a nomeação de uma via. Dessa maneira, temos que a nomeação, a homenagem, é significada pelos acontecimentos que ocorrem a sujeitos designados por um nome.

Esclarecida esta questão, consideremos nosso objeto de estudo: as nomeações da via. 0 primeiro texto que traremos para a reflexão será o da Lei no 6426, promulgada pelo Presidente da Câmara de São José do Rio Preto, Dourival Lemes dos Santos, em 23 de outubro de 1996, que instaura a substituição e a renomeação da rua em foco. Trata-se de um texto cujo objetivo está no Art. 1ํㅜㅇㅡ.

Art. 1을 Passa a denominar-se 'Zumbi dos Palmares' a atual Rua Domingos Jorge Velho, do Jardim Paulista.

Visto que já explicamos como se dá a performatividade enunciativa das Leis de nomeação de logradouros públicos, passaremos a considerar a relação e algumas questões entre os nomes que são colocados em cena, o de Domingos Jorge Velho e o de Zumbi dos Palmares. Primeiro, por que a substituição de nome? Segundo, há relação entre estes nomes? Terceiro, que acontecimentos são rememorados e recortados pelo presente da enunciação, da nomeação e da renomeação, para que se possa prestar uma homenagem, e designar essa rua por esses nomes?

Para compreendermos os sentidos do acontecimento da renomeação desta rua, na história da cidade, o que traremos para a análise, no entanto, será o projeto de lei no 0402/95 (Fig. 1), visto que é no projeto de lei que encontramos a "justificativa" da mudança do nome da rua.

\section{Figura $1^{1}$}

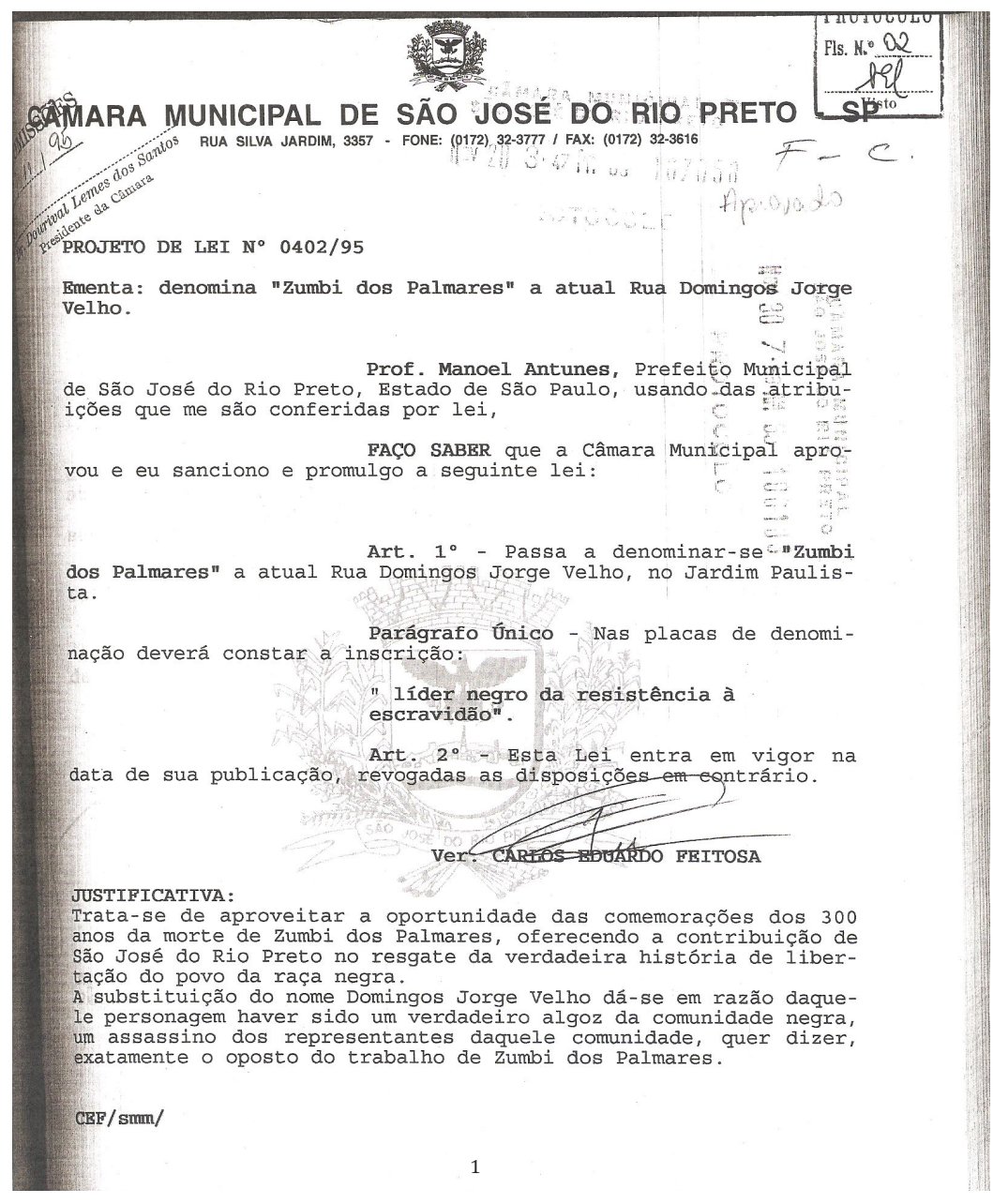

1 Projeto de Lei no 0402/95, retirado dos arquivos da Câmara Municipal de São José do Rio Preto. 
Para a análise, iremos considerar dois recortes deste texto: o Parágrafo Único e a Justificativa. Chamaremos, primeiramente, a atenção para a justificativa, para darmos continuidade à reflexão anterior.

Sobre a justificativa, podemos destacar duas questões: a) embora haja uma mudança de nome, há uma ligação entre as denominações, seja da ordem do tema, seja da ordem do acontecimento - a escravidão; b) a mudança do nome tem uma motivação, que é a de prestar uma homenagem, tentar resgatar um passado e sanar uma dívida histórica. No entanto, uma questão que deve ser examinada primeiro é: se Domingos Jorge Velho, segundo o projeto, é determinado pelas designações: "verdadeiro algoz da comunidade negra" e "assassino dos representantes daquela comunidade", como, em um primeiro momento, e considerando o que expõe a lei no885 sobre a nomeação de logradouros públicos, teve-se a intenção de significar uma rua com esse nome. Afinal, "algoz" e "assassino" embora sejam referências a trabalhos realizados com influência na vida coletiva, não significam, no contexto da escravidão, gestos de filantropia, de abnegação, e muito menos de heroísmo, como impõe o artigo promulgado em 1962.

Então, nos interessamos por investigar quais os sentidos e o que foi recortado como memorável para que pudéssemos considerar Domingos Jorge Velho um sujeito merecedor de homenagem para designar o nome de uma rua.

O texto que nos seria útil, da mesma forma que para compreendermos a renomeação seria o projeto de lei, ou a lei que instituiu esta denominação. Contudo, não encontramos no arquivo da Câmara Municipal de São José do Rio Preto tais documentos, sendo o único documento referente a esta denominação um Decreto (n⿳0119), de 19 de outubro de 1950, redigido a mão e em péssimo estado de conservação, o qual impõe a denominação oficial de nomes de várias ruas da cidade, inclusive a nomeação que nos interessa. Trata-se, na realidade, de uma lista com os nomes das ruas e suas localizações, os bairros os quais elas se encontram. O que, em um primeiro momento, poderia não parecer um lugar fecundante para investigarmos sobre a denominação do nosso objeto.

Entretanto, se considerarmos o conjunto das nomeações oficializadas pelo decreto, veremos que o bairro rio-pretense Jardim Paulista, no qual se encontra a rua que estudamos, teve todas as nomeações de suas vias oficializadas por este mesmo documento, o que possibilitou a configuração do bairro como segue no mapa (Fig. 2):

Figura $2^{2}$

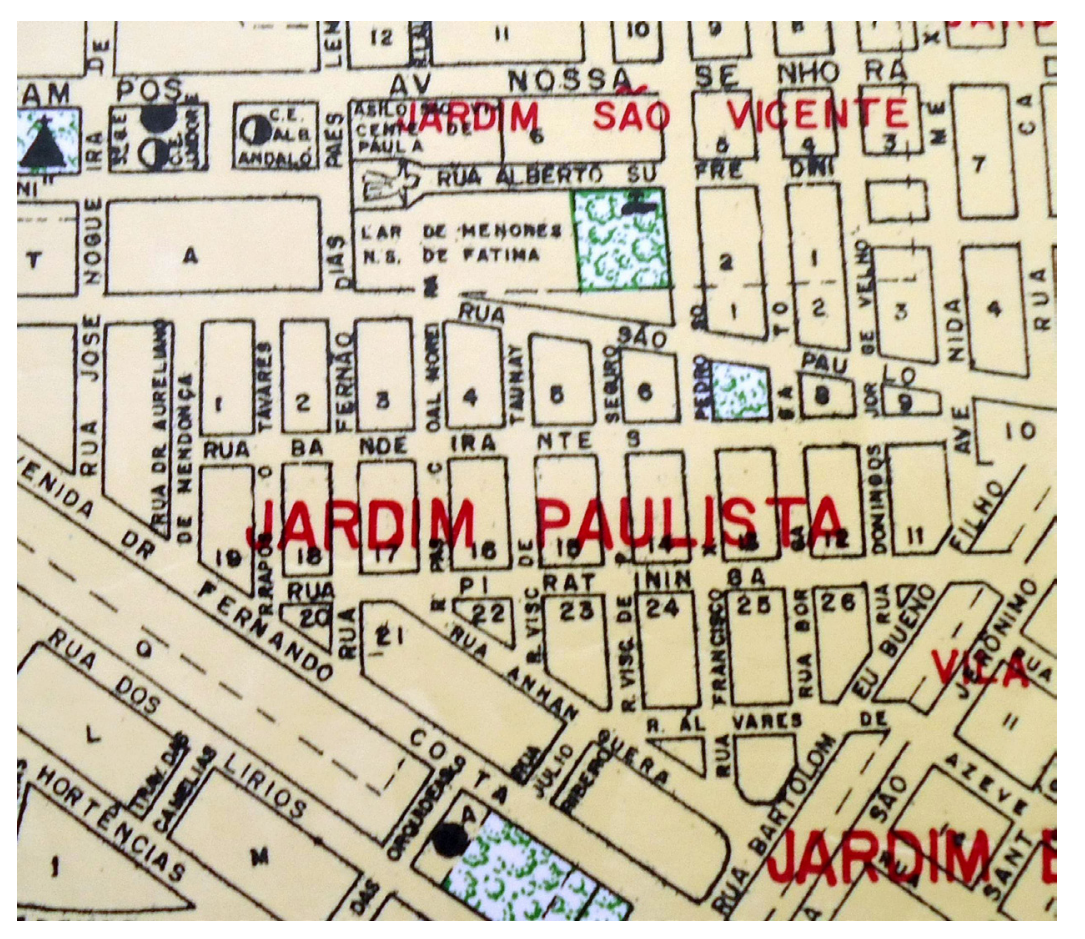

2 Realizamos um recorte do mapa da cidade de São José do Rio Preto, no qual pode ser melhor visualizado as ruas do bairro Jardim Paulista, o que facilitará nossa exposição da análise. O presente mapa, sem informação de autoria e data de produção, está disponível no Arquivo Municipal da cidade. 
Enfim, tomando o mapa como um texto de um acontecimento de linguagem (GUIMARÃES, 2001, p. 95), e levando em conta o decreto acima, vemos que todas as vias em sentido vertical receberam nomes próprios de pessoas, iniciando o bairro na Rua Raposo Tavares e sendo a última via Rua Bartolomeu Bueno Filho. Assim, se considerarmos estes nomes próprios enquanto nomes de rua, perceberemos que eles, mais do que instruir, são enunciados que significam no mapa, designando este espaço enquanto cidade (GUIMARÃES, 2001, p. 97).

Se somarmos ao mapa e ao decreto mais um tipo de material significante, as placas de denominação ${ }^{3}$ das devidas ruas, notaremos que no caso do Jardim Paulista a nomeação de suas vias não se dá em dispersão. Todas as nomeações de pessoas tomadas como memoráveis enunciam pertencimento a uma história brasileira, sendo em sua maioria "bandeirantes". Como podemos verificar nas seguintes placas (Fig. 3):

Figura $3^{4}$
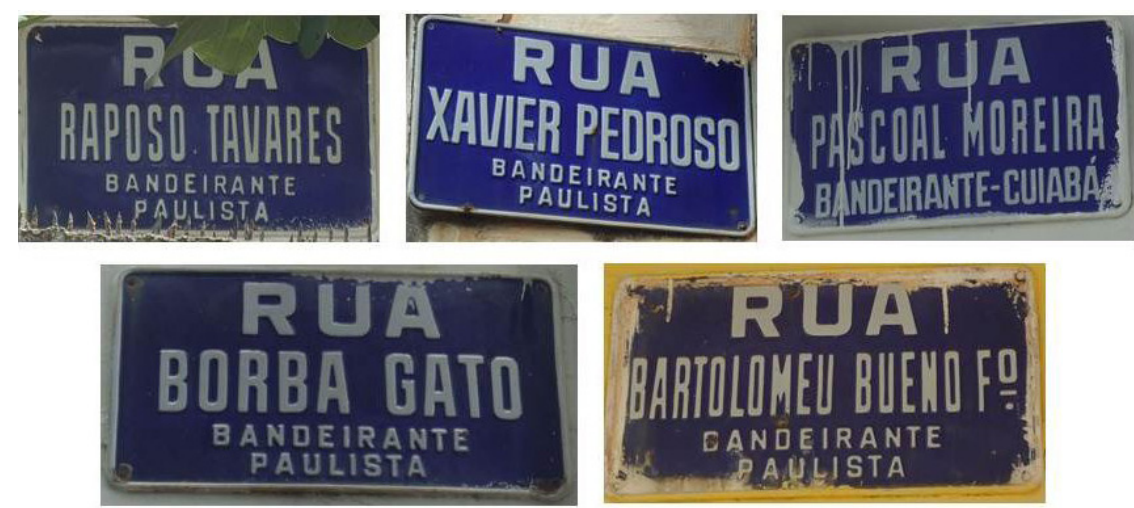

\footnotetext{
3 Verificamos que há uma variedade de tipos de placas nas ruas de São José do Rio Preto, no entanto, para este artigo consideramos apenas as placas metálicas, fixadas em casas, geralmente, de esquina, e

que contém uma espécie de aposto abaixo da nomeação do logradouro.
4 As outras vias verticais que estão dispostas no mapa fazem referência a escritores brasileiros do século XIX.Todas as fotografias de placas de rua apresentadas neste artigo são de nossa autoria.
}

O que nos chamou a atenção nestas placas foi a uniformidade dos apostos que reescrituram ${ }^{5}$ estes sujeitos da mesma forma, "bandeirante", sendo, com a exceção da Rua Pascoal Moreira, paulistas. Embora não tenhamos mais a placa da Rua Domingos Jorge Velho, visto que esta foi substituída pela de denominação Rua Zumbi dos Palmares, sabemos que aquele foi, da mesma forma que esses, um bandeirante. Porém, além de enunciar pertencimento a uma história brasileira, que sentidos foram rememorados para estes sujeitos, para significar as ruas deste bairro? O que significa a designação "bandeirante paulista"?

Considerando o mapa, veremos que a rua, em sentido horizontal, que atravessa todas as vias verticais do bairro, foi denominada de Rua Bandeirantes, cuja placa é a que segue (Fig. 4):

Figura 4

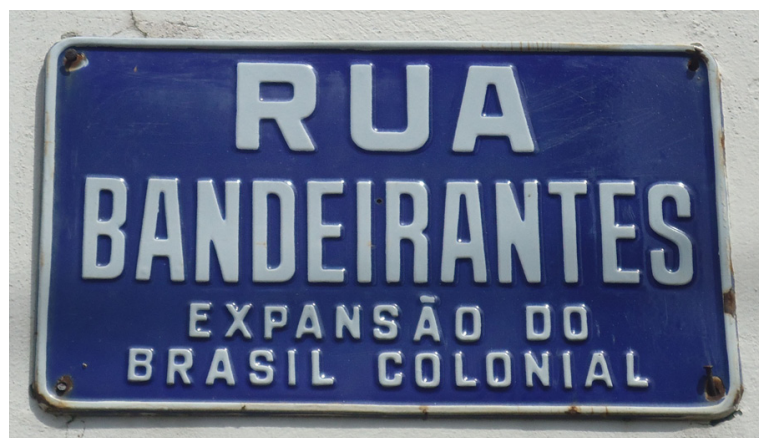

Ora, a nomeação desta via, também oficializada no decreto no 119, nos mostra uma continuidade na organização do memorável do acontecimento das nomeações deste bairro, pois, segundo o mapa, observa-se que o

${ }^{5}$ Consideramos que a relação apositiva apresentada nestas placas pode ser descrita como uma reescrituração (GUIMARÃES, 2012, p.2). Para Guimarães (2009, p.53), a reescrituração é o procedimento enunciativo que "consiste em redizer o que já foi dito". 
funcionamento semântico-enunciativo destas nomeações significa tanto geográfica como historicamente, visto que são nomeações que se dão em conjunto. Ou seja, sobre as placas de denominação, vemos que a enunciação de Rua Borba Gato, Rua Xavier Pedroso, etc., no mapa, ao se darem como instruções semânticas, ou seja, como indicações para acesso ao mundo (GUIMARÃES, 2001, p.98), o fazem pela constituição de memoráveis de um acontecimento que é o mesmo, o do movimento bandeirante.

Se considerarmos a reescrituração apositiva que apresenta a placa da Rua Bandeirantes, "Expansão do Brasil Colonial", e o que determina a Lei no885 como condição para as ruas receberem nomes de pessoa, que é o fato do sujeito ter realizado, "gestos de filantropia, de abnegação ou heroísmo", veremos que o que é recortado como memorável para a nomeação desta rua, o que significa as outras conjuntamente, é uma história de heroísmo, visto que é a imagem de herói que pousa sobre os bandeirantes quando os consideram "responsáveis pela expansão do Brasil colonial". Assim, mesmo que a palavra "expansão" permita uma série de outros gestos de interpretação, pelo que propõe o texto da lei no 885 , sentidos são silenciados para que a nomeação seja justificada e para que a homenagem possa ser feita.

Sobre a denominação de outras vias do bairro, percebemos que além da Rua Bandeirantes, outras duas vias cortam o bairro: a Rua São Paulo, e a Rua Piratininga (Fig. 5).

Figura 5

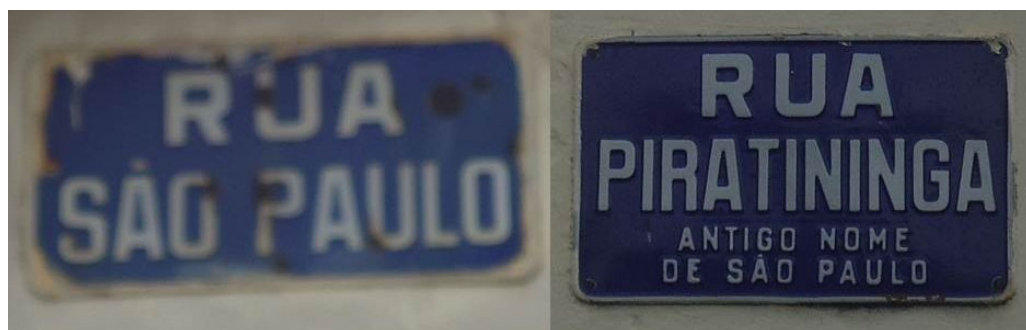

No mapa, a Rua São Paulo corta horizontalmente o bairro e está acima da Rua Bandeirantes, e a Rua Piratininga, também na horizontal, está abaixo da mesma. Juntas, estas três vias cortam paralelamente todas as outras ruas com nomes de bandeirantes do bairro. Piratininga, como se designa na placa, foi o primeiro nome da cidade de São Paulo e também o nome do Planalto que separava este território do litoral. Como se sabe, a cidade de São Paulo surge com a construção de um colégio jesuíta, "Colégio de São Paulo de Piratininga", que tinha por finalidade a catequização dos índios do Planalto de Piratininga. O nome São Paulo foi escolhido, pois o dia da fundação do colégio foi 25 de janeiro, dia em que a Igreja católica celebra a conversão do Apóstolo Paulo. Deste modo, compreendendo o mapa como o texto de um acontecimento de linguagem, ou seja, considerando os acontecimentos históricos que determinam e significam o que está disposto nestas placas e o que está espacializado e enunciado no mapa, vemos que o que se recorta como memorável, mais do que um marco de pertencimento a uma história brasileira, é, especificamente, um acontecimento da história do desenvolvimento de um estado, visto que se conta pela nomeação destas ruas os marcos iniciais da expansão deste, o que está fortemente e simbolicamente representado no nome do bairro: Jardim Paulista.

Enfim, o percurso que efetivamos responde, de alguma forma, à pergunta que fizemos inicialmente: os sentidos e o que foi recortado como memorável para que se pudesse considerar Domingos Jorge Velho um sujeito mérito de homenagem para designar o nome de uma rua, foi o fato deste ter sido um bandeirante. Em resumo, podemos considerar o seguinte DSD $^{6}$ para a nomeação desta rua:

6 O DSD ou Domínio Semântico de Determinação é um conceito desenvolvido por Eduardo Guimarães para representar as relações de sentido de palavras e expressões linguísticas (GUIMARÃES, 2007b, p.77-96). No DSD estas relações são apresentadas por uma escrita própria, com sinais específicos: $\vdash,-1, \perp$ e T significam "determina" e expõem relações de sinonímia; e um traço como —_, dividindo um domínio, significa antonímia. 
RESPONSÁVEL PELA EXPANSÃO DO BRASIL COLONIAL

$$
\stackrel{\perp}{\perp} \underset{\perp}{\perp}
$$

RUA DOMINGOS JORGE VELHO

Podemos ler o DSD acima da seguinte forma: ser responsável pela expansão do Brasil enquanto colônia determina o sentido que é recortado para Bandeirante, que determina o sentido que é rememorado e se recorta para o sujeito que dá nome à rua, e que, por sua vez, determina o sentido para São Paulo que o nome do bairro, Jardim Paulista, recorta: território de bandeirantes, território de expansão do Brasil colonial.

Por meio da construção desse DSD, vemos que o que se recorta como fato a saber da história para denominar essa rua com o nome de Domingos Jorge Velho, foi o fato deste indivíduo ter prestado uma contribuição heroica e com repercussão notória para com a história paulista/brasileira. No entanto, vemos, em contrapartida, pela justificativa do projeto de Lei que instaura a renomeação da via, que o que se recorta como memorável para significar essa rua da cidade mantém uma relação de antonímia com o sentido que se recupera para nomeá-la. Dessa maneira, considerando as reescriturações de Domingos Jorge Velho na justificativa do Projeto, temos para a destituição da nomeação a seguinte relação de determinação:

\section{VERDADEIRO ALGOZ \\ DA COMUNIDADE NEGRA}

\section{ASSASSINO DOS REPRESENTANTES}

DA COMUNIDADE NEGRA
RUA DOMINGOS JORGE VELHO

RUA ZUMBI DOS PALMARES
Vemos por meio desse DSD que o que determina a substituição é o fato de Domingos Jorge Velho ser reescriturado, na justificativa do Projeto, por verdadeiro algoz da comunidade negra e assassino dos representantes dessa mesma comunidade, o que o coloca no acontecimento da renomeação em oposição a Zumbi dos Palmares.

Desse modo, sobre o acontecimento da nomeação e o da substituição do nome, vemos que um mesmo nome, Domingos Jorge Velho, designa em momentos enunciativos diferentes, coisas distintas, o que nos mostra de forma direta que uma coisa é um nome, outra é aquilo que ele designa. Sobre este fato, há algo em Bréal (2008), sobre como os nomes são dados às coisas que vale a pena ser lembrado aqui.

Para o semanticista: "não há dúvida de que a linguagem designa as coisas de modo incompleto e inexato" (BRÉAL, 2008, p. 123). Se considerarmos as designações que são atribuídas ao nome de Domingos Jorge Velho, vemos que o precursor da semântica estava correto, afinal, observa-se que, no acontecimento da nomeação, o que se recortou como memorável para designar o nome foi o fato de este ser um "bandeirante", ou seja, um dos sujeitos responsáveis pela expansão do território nacional, e não o seu caráter escravagista, o algoz, o assassino, o que mostra exatamente o quanto de inexato e incompleto um nome pode designar, visto que são as designações que determinam tanto a nomeação quanto a substituição do nome para a via. O novo ato legislativo, então, confere um novo sentido à "expansão do Brasil colonial", operando ressignificações em todo o mapa do bairro.

Notamos que o nome de Domingos Jorge Velho, ao funcionar em cenas enunciativas diferentes, apresentam designações que são significadas de acordo com o que se recorta como memorável por um locutor em cada um dos momentos enunciativos, o da nomeação e o da substituição. Vemos que há um esquecimento que produz sentido e permite a nomeação, e uma recuperação deste apagamento que autoriza a substituição do nome. Assim, 
há uma divisão do locutor, em cenas enunciativas distintas, que significa os fatos.

Enfim, compreendido o fato da nomeação e o da substituição, iremos agora tratar do acontecimento da renomeação. Deste acontecimento, uma primeira questão que nos chama a atenção é a relação entre os nomes de Domingos Jorge Velho e Zumbi dos Palmares. Tanto Zumbi quanto Jorge Velho são personagens que contribuíram para a história do Brasil, inclusive, compartilhando uma história em comum, visto a grande quantidade de narrativas em que os dois nomes aparecem ao se referir a um mesmo acontecimento: a preservação e a destruição do Quilombo dos Palmares. Se considerarmos mais uma vez a justificativa do projeto de Lei da renomeação, veremos como efeito deste gesto o estabelecimento de uma relação ${ }^{7}$ de antonímia entre os sujeitos homenageados.

Na cena enunciativa da renomeação, vemos manifestar não apenas uma questão de homenagem, mas se observa também a questão de reparar uma dívida histórica, como efeito de um rearranjo do mapa provocado pela emergência de um ato de renomeação, sendo que o locutor não significa apenas enquanto locutor-administrador. Vemos um locutor posicionado, e de um lugar de dizer que não é apenas do discurso administrativo, e sim de um discurso reivindicador. Na certa, pois sabemos que a mudança do nome desta rua foi motivada por uma ação social, de acordo com artigo de Romildo Sant'Anna, intitulado, inclusive, "Consciência Negra".

Verificamos também que o projeto de Lei, em parágrafo único, institui que a placa de denominação deve conter a inscrição "líder negro de resistência à escravidão", aposto que reescritura Zumbi dos Palmares. No

\footnotetext{
Vale ressaltar que, para Guimarães (2007, p.80), “[...] um DSD é construído pela análise das relações de uma palavra com as outras que a determinam em textos em que funciona. Deste modo podemos dizer o que significa uma palavra num certo texto, num conjunto de textos relacionados por algum critério que os reúna: do mesmo autor, sobre um certo assunto, de um certo momento, etc.".
}

entanto, não encontramos em nenhuma placa desta rua esSa designação, porém, acreditamos que em algum momento houve uma placa com uma designação, o que também é citado no artigo de Sant'Anna, que há pouco mencionamos. Contudo, segundo o jornalista, o explicativo que constava na placa era: "Herói da Raça Negra".

De qualquer forma, ao compreendermos as reescriturações "líder negro da resistência à escravidão" e "herói da raça negra", vemos que o que o presente do acontecimento da renomeação recorta como memorável significa este sujeito enquanto um herói da história, o que pode ser melhor visualizado no seguinte DSD:

LÍDER NEGRO DA RESISTÊNCIA À ESCRAVIDÃO

HERÓI DA RAÇA NEGRA

RUA ZUMBI DOS PALMARES

RUA DOMINGOS JORGE VELHO

Podemos ler o DSD acima da seguinte maneira: líder negro da resistência à escravidão e herói da raça negra são reescriturações que determinam o memorável que atribui sentido a Zumbi dos Palmares, o que o autoriza a ser homenageado como um nome de rua, colocando-o, assim, em relação de antonímia com Domingos Jorge Velho, segundo o texto do Projeto de Lei. Portanto, as reescriturações designam Zumbi segundo o seu papel na história, o que o enquadra no que determina a Lei no 885 , visto que ser um líder de resistência ou um herói são gestos que autorizam que o nome deste sujeito nomeie a via. Para Guimarães: 
A particularização da reescrituração pode ser considerada como ligada ao funcionamento específico do nome próprio [...] o agenciamento da enunciação de nomeação de alguém, por um nome próprio, estabelece uma relação de inseparabilidade do nome e da pessoa nomeada pelo vínculo do acontecimento que nomeia à pessoa nomeada. E este vínculo se projeta para todas as enunciações futuras do nome, é um futuro para sempre próprio do acontecimento da nomeação. É esta futuridade que acompanha todo funcionamento de um nome próprio, e dá a ele esta capacidade particularizadora (GUIMARÃES, 2012, p. 5)

Desse modo, verificamos que tanto a reescrituração presente no parágrafo único do Projeto de Lei, líder negro de resistência à escravidão, quanto a que a notícia de Sant'Anna diz ter sido fixada nas placas de denominação da rua, herói da raça negra, estabelecem uma relação de inseparabilidade entre o nome próprio e quem ele designa, o que cria um agenciamento específico vinculado a esse nome de rua, que projeta um futuro de enunciações pelas quais se falará do nomeado através de um nome que é designado pelas reescriturações acima, e que passa a significar essa rua da cidade.

No entanto, vale destacar que há um movimento interessante na passagem de líder negro de resistência à escravidão para herói da raça negra, o que permite que não signifiquemos estes apostos como sinônimos, embora ambos autorizem a nomeação da rua com este nome.

Não há relação sinonímica, pois o que particulariza Zumbi na reescrituração do Projeto de Lei é o seu caráter de liderança e de resistência a um acontecimento único, a escravidão. Já a inscrição "herói da raça negra" reduz a importância deste sujeito para com toda uma raça, e passa-se a significar a "negritude" de um povo pela escravidão, ele passa a ser uma abstração restrita a uma parcela do povo. Assim, as duas reescriturações enunciadas recortam conhecimentos a respeito do sujeito nomeado que são significados diferentemente, porém, sem estabelecer uma relação de antonímia.
Sobre o funcionamento morfossintático do nome Zumbi dos Palmares, há que se ressaltar outro aspecto que significa esta análise. Vemos que dissemelhante de Domingos Jorge Velho, que é um nome que se dá por justaposição, aquele se dá por meio de uma preposição. Logo, duas questões podem ser colocadas: o da origem do nome Zumbi e a sua construção com a preposição.

Mais uma vez trazemos Bréal para a nossa análise. Quando o semanticista nos fala sobre o Mito de Édipo (1998), ele faz um gesto decisivo para a constituição da semântica: ele rompe com a concepção etimológica da significação (GUIMARÃES, 1998, p. 90-91). Compartilhando deste pensamento, podemos ver que há um movimento de significação que é atribuído ao nome de Zumbi dos Palmares.

O Dicionário Brasileiro da Língua Portuguesa, de Antonio Joaquim de Macedo Soares, edição de 1955, traz a palavra zumbi como entrada. Segundo o verbete, zumbi é uma palavra angolense que quer dizer "Alma do Outro Mundo", ou ainda pode ser a corrupção de Zambi, que significa Deus, afirmações que o dicionarista aponta no meio do verbete. No entanto, vale destacar dois recortes deste texto lexicográfico:

[...] Zambi é o espírito que ninguém vê, é a coisa do outro mundo, é a alma separada do corpo ou que nunca teve corpo, é o maravilhoso, o quid incognitum, a voz do trovão, o fulgor do raio, potente força da natureza, da qual os pobres negros fazem idéia tão perfeita como nós do nosso Deus trino e uno, igualmente misterioso e incognoscível [...] (MACEDO SOARES, 1955, p. 203).

[...] O chefe dos Palmares era Zumbi ou Zambi; pois de ambas as formas achamos nos escritores do tempo. Na linguagem popular, zumbi é também o manda-chuva, a influência política da freguesia, de ordinário algum tratante que vive de ser chefe de partido [...] (MACEDO SOARES, 1955, p. 203).

O que os dois recortes nos mostram é exatamente aquilo que Bréal nos aponta, há uma polissemia de sentidos para zumbi que a história lhe atribui, por esta palavra passar a significar enquanto um nome próprio de pessoa a Zumbi dos Palmares. Para o semanticista, "à medida que uma significação 
nova é dada à palavra, parece multiplicar-se e produzir exemplares novos, semelhantes na forma, mas diferentes no valor" (BRÉAL, 2008, p.103). Vemos que a não homogeneidade se dá, exatamente, pelo papel que exerceu Zumbi na história da escravidão. Se a etimologia traz zumbi, como "alma de outro mundo", o que vemos significar é a forma autônoma como ela passou a significar, ao se tornar um nome próprio de pessoa, através da história dos textos nos quais esteve (GUIMARÃES, 1998, p. 91).

Vale destacar que antes de ser Zumbi dos Palmares, ao ser capturado por soldados, com sete anos de idade, foi ele nomeado pelo padre António Melo, responsável pela sua formação, de Francisco. Aos quinze anos ele foge, e começa aí sua história enquanto Zumbi dos Palmares.

Notamos, então, que há uma outra questão que se coloca que é a necessidade de manter o nome que faz referência à sua origem, um nome quimbundo, angolano, o que já simboliza uma atitude de resistência. No entanto, o que vemos significar não é o sentido etimológico do nome, como as narrativas e o verbete analisado nos mostra. 0 que temos, na verdade, é uma mudança de sentido para zumbi, que a partir da atitude deste sujeito passa a significar sinônimo de liderança. Vemos, assim, que é um determinado acontecimento que faz significar este nome, ou seja, nomear, como se mostra aqui, "é estar na memória" (GUIMARÃES, 2002, p. 14), e ser afetado por ela.

Na composição desse nome próprio, há outro aspecto considerável, que é o sobrenome. 0 que funciona como um sobrenome para Zumbi não significa apenas como identificação de um indivíduo para o Estado e para a sociedade, mas marca um pertencimento desse sujeito a uma comunidade, a um quilombo, o que pode ser observado, morfossintaticamente, pela ligação entre o nome e o que funciona como sobrenome, feita por meio de uma preposição e um determinante (artigo).

Essa construção significa uma unicidade (GUIMARÃES, 2002, p. 35) desse nome próprio. Operam-se assim duas relações importantes: uma individualização instituída por Zumbi, e uma relação com o lugar ao qual pertence, dos Palmares, o que é dado pelo próprio processo de designação. Vemos, portanto, como o funcionamento referencial deste nome "é produzido por um procedimento do processo de identificação social" (GUIMARÃES, 2002, p. 41).

\section{Figura $6^{8}$}

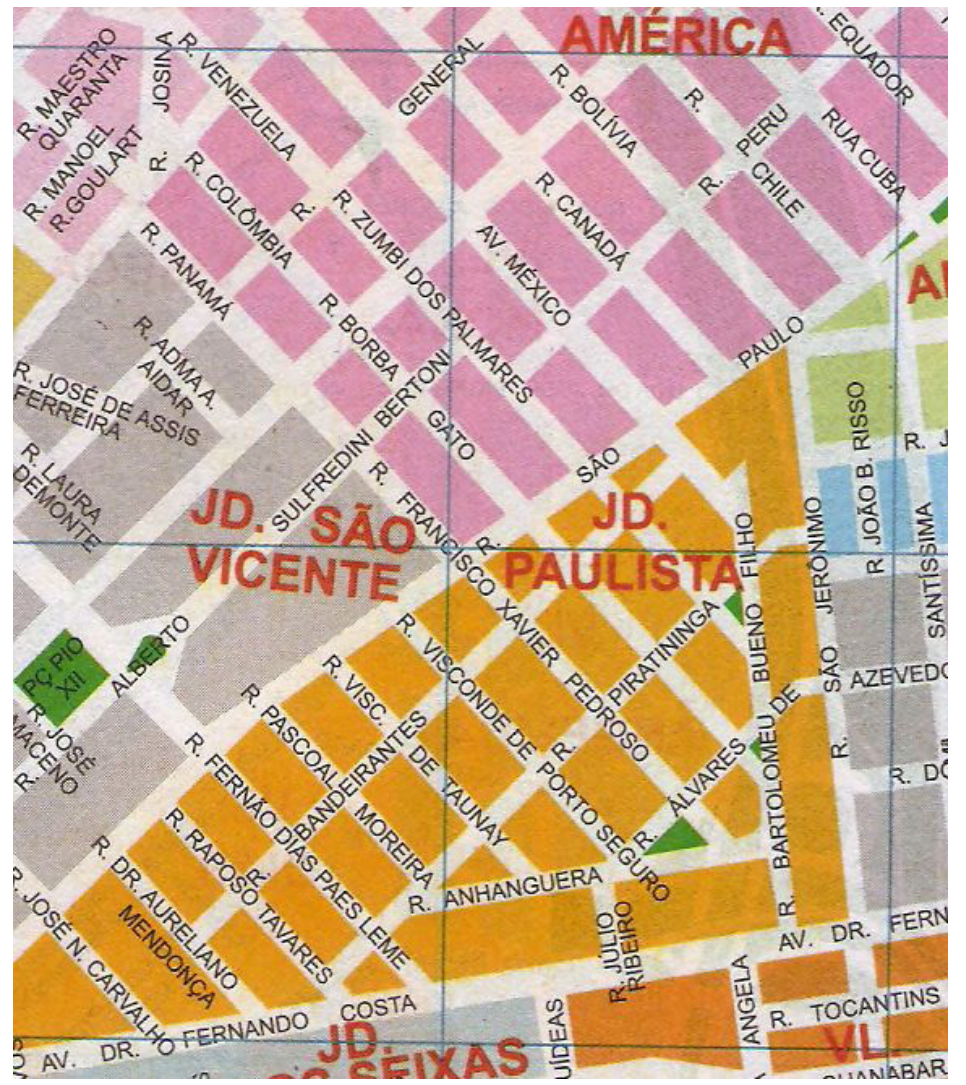

8 O presente mapa, que também é um recorte efetuado por nós, está disponível no GuiaSEI 2013/2014 da cidade de São José do Rio Preto. 
Esse percurso nos mostra que a entrada do nome Zumbi dos Palmares na configuração do mapa do bairro Jardim Paulista ressignifica todo o funcionamento semântico que foi construído para este, não trazendo apenas uma mudança de sentido para uma rua.

A nomeação Rua Zumbi dos Palmares faz rememorar algo que estava silenciado sobre o movimento bandeirante, fazendo os nomes dessas ruas significarem agora por uma outra atividade, a de colaboradores do processo de escravização de negros e índios. Ao trazer uma outra história como memorável, vemos significar, no conjunto desses nomes, um aspecto esquecido, o que nos mostra que a temporalidade do acontecimento da renomeação descreve o memorável que o constitui, por meio de um nome, e que traz outras enunciações para significar esse acontecimento.

Enfim, as observações lançadas neste artigo só foram possíveis, pois não tomamos como corpus simplesmente os nomes das ruas (as placas), mas, outras materialidades significantes, como o mapa do bairro e os documentos que legislam sobre o processo de nomeação de ruas do município. Olhamos, então, a relação integrativa dos nomes, e seus sentidos, e a sua distribuição no mapa, pois só assim pudemos verificar como o espaço urbano é historicamente constituído de sentido.

\section{Considerações finais}

Uma primeira coisa a dizer: estamos diante de materiais de linguagem que significam diferentemente uns dos outros e também os processos que buscamos compreender. Logo, cada texto apresenta certas especificidades de sentidos e questões que valeriam a pena ser mais bem detalhados em outro momento. No entanto, podemos dizer que esses textos se instauram em uma rede de significação que os une, fazendo com que seja possível compreendermos os sentidos da nomeação e da renomeação de uma rua da cidade.
Como nos aponta Guimarães (2002, p. 47), "a enunciação dos nomes de ruas é sempre uma enunciação sobre outra enunciação". Sobre o fato da nomeação e da renomeação, vemos que é exatamente o que se recorta como memorável, pelo presente da enunciação desses dois momentos sobre um acontecimento, o que faz significar uma mesma rua de forma diferente. Trata-se de nomes que recortam, como memoráveis, narrativas diferentes de um fato da história colonial brasileira, atualizando sentidos para essa história.

Sobre a nomeação, temos que a escolha por Domingos Jorge Velho se deu pelo fato heroico de este ter sido um bandeirante, um dos responsáveis pela "expansão do Brasil colonial". Contudo, em outro momento, observamos que o que se recorta como memorável para substituir esse nome é algo que foi silenciado em um primeiro momento, o fato de este sujeito ter sido um "algoz da comunidade negra", um "assassino", e, inclusive, o aniquilador do Quilombo dos Palmares, fato que nos permite fazer a ligação com o sujeito que passou a nomear a mesma via da cidade.

Sobre a renomeação, vemos que ao recortar como memorável o fato de Zumbi dos Palmares ter sido um líder de resistência à escravidão, tenta-se, além de prestar uma homenagem, restituir uma dívida histórica. $O$ que vemos é que o lugar social do locutor-administrador é constituído pelo memorável dos direitos humanos, o que muda os sentidos que eram atribuídos para uma rua e um bairro. Ao fazer figurar o nome de Zumbi dos Palmares no mapa do bairro, vemos surgir novos sentidos para a história que é representada no mapa, sentidos que foram silenciados no momento da nomeação.

Compreendemos, portanto, que o modo de significar os espaços da cidade mostra que eles são espaços simbólicos e políticos. Podemos notar que as reescriturações que são atribuídas aos dois sujeitos, em enunciações diferentes, e em textualidades diferentes, apresentam um papel fundamental na compreensão dos sentidos que são atribuídos aos sujeitos e à rua. Vemos 
que o que as reescriturações predicam aos nomes é exatamente o que os locutores dessas enunciações recortam como passado, como memorável para significá-los, e, nesse sentido, que se faz surgir o político, ou seja, o "que é próprio da divisão que afeta materialmente a linguagem” (GUIMARÃES, 2002, p. 15) e faz significar esses sujeitos e a rua que denominam.

O que podemos concluir, a partir deste percurso de análise, é que um nome nunca nos diz tudo sobre o objeto que refere, visto que as formas de identificar, significar por um mesmo nome, nos leva a caminhos opostos de sentido, como pudemos verificar. Aquilo que um nome designa permite, em enunciações distintas, identificar um mesmo nome de formas dissemelhantes. Como nos mostra Guimarães, o acontecimento instaura a sua própria temporalidade; dessa forma, podemos dizer que os diferentes recortes de textos mobilizados em nossa análise significam por rememorações diferentes que nomearam ora Domingos Jorge Velho, ora Zumbi dos Palmares, como sujeitos merecedores de homenagem, e aptos, ou não, para nomear, significar uma rua da cidade.

\section{Referências}

BRÉAL, Michel. 0 mito de Édipo. In: Línguas e Instrumentos Linguísticos, Campinas, n. 2, p. 69-84, jul.-dez. 1998.

Ensaio de Semântica: ciência das significações. Trad. de Eduardo Guimarães. 2. ed. Campinas: Editora RG, 2008.

GUIMARÃES, Eduardo. Aposto e nome próprio. In: Entremeios: revista de estudos do discurso, Campinas, n. 5, p. 1-8, jul. 2012.

Em torno de um nome próprio de cidade sobre a produção dos sentidos de uma origem. In: Cadernos de Estudos Linguísticos, Campinas, v. 53, n. 2, p. 137-147, jul.-dez. 2011.

. Análise de Texto: procedimentos, análises, ensino. Campinas: Editora RG, 2011b.

A enumeração: funcionamento enunciativo e sentido. In: Cadernos de Estudos Linguísticos, Campinas, v. 51, n. 1, p. 49-68, jan.-jun. 2009.
Texto \& Argumentação: um estudo de conjunções do português. 4. ed. Campinas: Pontes, 2007.

. Domínio Semântico de Determinação. In: GUIMARÃES, Eduardo; MOLLICA, M. C. (Org.). A palavra: forma e sentido. Campinas: Pontes, 2007b. p. 77-96.

Semântica do Acontecimento: um estudo enunciativo da designação. Campinas Pontes, 2002.

. Um mapa e suas ruas. In: ORLANDI, E. P. (Org.). Cidade Atravessada: os sentidos públicos no espaço urbano. Campinas: Pontes, 2001. p. 95-100.

. Linguagem e Mito: uma Concepção de Sentido e de Texto. In: Línguas e Instrumentos Linguísticos, Campinas, n. 2, p. 85-92, jul.-dez. 1998.

. Designação e espaço de enunciação: um encontro político no cotidiano. In: Letras (Santa Maria), Santa Maria, n.26, p. 53-62, 1991.

MACEDO SOARES, Antônio Joaquim de. Dicionário Brasileiro da Língua Portuguesa. (1888). Vol. II. Rio de Janeiro: Ministério da Educação e da Cultura, Instituto Nacional do Livro, 1955.

SANT'ANNA, Romildo. Consciência Negra. In: Diarioweb. Disponível em: <http://www. diarioweb.com.br/editorial/corpo_noticia.asp?IdCategoria=62\&IdNoticia=12673>. Acesso em: 10 out. 2013 .

Recebido em 29/08/2015. Aceito em 23/12/2015. 